\title{
Arylsulphatase A activity and sulphatide concentration in placenta, membranes and cord after delivery
}

\author{
Ugo Indraccolo ${ }^{1, *}$, Enea Traini ${ }^{2}$, Emilia Baldoni ${ }^{2}$, \\ Salvatore Renato Indraccolo ${ }^{3}$ and Lucia \\ Vitaioli $^{2}$ \\ ${ }^{1}$ Department of Surgical Sciences, Institute of \\ Obstetrics and Gynecology, University of Foggia, \\ Foggia, Italy \\ 2 Department of Comparative Morphological and \\ Biochemical Sciences, University of Camerino, \\ Camerino, Italy \\ ${ }^{3}$ Department of Gynecology, Perinatology and Child \\ Welfare, II Faculty of Medicine and Surgery, "La \\ Sapienza" University, Rome, Italy
}

\begin{abstract}
Aim: We evaluated variations in behavior of arylsulphatase $A$ activity (an enzyme that catabolizes sulphatides) and of sulphatide concentration in the placenta, cord and membranes of healthy gravidas at term pregnancy, following spontaneous birth.

Methods: We extracted and biochemically determined arylsulphatase $\mathrm{A}$ and sulphatide concentration in placenta, cord and membranes (far from and close to internal uterine os) in 14 patients.

Results: Activity of arylsulphatase A decreased in the cord, in membranes far from the internal uterine os, in membranes close to the internal uterine os and in the placenta. Sulphatide concentration was minimal in the cord and maximal in placenta, with intermediate values in the membranes. No correlation was found between arylsulphatase $A$ activity and sulphatide concentration, nor among arylsulphatase A activities, nor among sulphatide concentrations among the different tissues. It seems that multiparity may increase and the duration of active labor may decrease arylsulphatase A activity in membranes far from the internal uterine os, while active labor duration does not appear to have any implication on sulphatide concentration in membranes close to the internal uterine os.
\end{abstract}

Conclusions: Arylsulphatase A activities and sulphatide concentrations in fetal adnexa show significant differences.

\footnotetext{
${ }^{*}$ Corresponding author:

Dr. Ugo Indraccolo, MD, PhD

Via Montagnano 16

62032 Camerino (MC)

Italy

Tel.: + 393286180677

Fax: +390737636668

E-mail: ugo.indraccolo@libero.it
}

Keywords: Arylsulphatase A; fetal adnexa; labor; sulphatides.

\section{Introduction}

Arylsulphatase $A$ is a lysosomal enzyme that catabolizes sulphatides. Arylsulphatase $A$ is likely to be under hormonal control, in particular, by estradiol and progesterone, since changes of the enzymatic activity are observed with various levels of serum estradiol and progesterone. Progesterone seems to increase and estradiol seems to decrease arylsulphatase A activity, consequently reducing or increasing sulphatide concentrations in tissues that are sensitive to such hormones [9, 20, 26, 39]. In addition, various authors have reported a possible arylsulphatase $\mathrm{A}$ inhibition mediated by cortisol on cell cultures as well [19, 23, 36].

It appears that the complex mechanisms determining onset of labor in primates can be related to changes in sex hormone sensitivity in decidua, membranes and placenta, possibly mediated by cortisol produced by the mature fetus in progressively increasing quantities [14, $25,27,34,35]$. Due to the steroid hormone effects on arylsulphatase $A$ activity, this enzyme might reflect the overall biological effect of progesterone, estrogens and cortisol - hormones which are implicated in initiating labor and active on human membranes and placenta.

On the basis of this theory, some of our previous research $[5,6]$ investigated the behavior of arylsulphatase A activity and sulphatide concentrations in maternal decidua before onset of labor, between 38 and 42 weeks' gestation, showing that arylsulphatase $A$ activity seems to decrease in an apparently exponential manner with the progression of pregnancy, thereby suggesting that such pattern could reflect a hormonal change related to the initiation of labor. Since the placenta and amniochorial membranes are implicated in onset of labor due to their diverse sensitivity to estrogens, progesterone and cortisol $[10,12,15,22,37,40,41]$ one would expect a diverse arylsulphatase $A$ activity and, consequently, a varying sulphatide concentration in these tissues once labor has begun. This study is aimed at testing this hypothesis.

\section{Patients and methods}

Between 2005 and 2006, samples were obtained from amniochorial membranes, placenta and cord following birth at the end 
of pregnancy in patients without gestational or labor pathology (gestational diabetes mellitus, preeclampsia, placenta previa, low birth weight, suspect of infections, premature rupture of membranes, labor induction, etc.). Gestational age was established by first trimester ultrasound, and calculated on an ordinal scale (for example 40 weeks and 4 days were considered as the $41^{\text {st }}$ week of gestation). The number of previous spontaneous births was obtained by patient interview. Duration of active labor was calculated from $4 \mathrm{~cm}$ dilation in the presence of uterine contractions. Labor duration was expressed in hours and rounded off by $30 \mathrm{~min}$. This decision was justified since the precise timing of active labor is difficult to determine.

Tissue samples were obtained as follows. A $2-3 \mathrm{~cm}$ segment of cord was obtained from its approximate mid-way point. A double specimen was obtained from the membranes: one close to the internal uterine os (corresponding to the lower uterine pole) and one far from the internal uterine os. This method is justified since the lower uterine pole may be implicated in labor and membrane rupture in a different way with respect to the remaining membranes [24]. Specimens of membrane considered as adjacent to the internal uterine os were obtained after having identified the point of rupture of lower uterine pole (excluding the cases of eccentric rupture of membrane and the cases in which membranes were not considered complete during postpartum examination). A ring of about $1 \mathrm{~cm}$ of membrane from around the rupture zone was, therefore, cut. Subsequently amniochorial membranes far from internal uterine os were also cut by scalpel, obtaining a tissue area of $\sim 3 \mathrm{~cm} \times 3 \mathrm{~cm}$ from the placental edge. Finally, a placental cotyledone was obtained from the center of the placental disk, on the maternal surface, without severing the fetal surface.

Specimens were stored at $-20^{\circ} \mathrm{C}$ simultaneously. p-Nitrocathecol sulphate and standard polar lipids mixture (Sigma Aldrich Chemical Co., St. Louis, MO) and other chemicals (Serva, Heidelberg, Germany) were used. We used the $0.25 \mathrm{~mm}$ percoated silica gel plates, utilized for thin-layer chromatography (TLC, Merck Co., Darmstadt, Germany).

Extraction and separation of sulphatides were carried out according to a method adapted from Bolognani [7], which consisted of homogenizing the samples in chloroform/methanol (2:1 $\mathrm{v} / \mathrm{v}$ ) and filtering the extract though a sintered glass filter with a vacuum pump connection. $\mathrm{KCl}(0.88 \%)$ was added to the filtrate and, after stirring, the covered tube was left until the separation phase (aqueous phase and organic phase) occurred. The organic phase was analyzed by spectrophotometry for sulphatides, using a $0.15 \mathrm{mM}$ Azure A solution in $0.05 \mathrm{~N} \mathrm{H}_{2} \mathrm{SO}_{4}$ as stain [21]. Absorbance was measured at $640 \mathrm{~nm}$ against a standard containing $70 \mathrm{mg} / \mathrm{g}$ of sulphatides. Concentration was expressed as $\mathrm{ng} / \mathrm{g}$ of fresh tissue.

The organic phase utilized thin-layer chromatography (TLC) separation on a $0.25-\mathrm{mm}$ silica gel plate. The lipids were separated on the same plate using a solvent mixture of chloroformmethanol-water (70:30:5 by volume) and compared with a standard polar lipid mixture (phosphatidylcholine, sulphatides, phosphatidyl-ethanolamine and cerebrosides). The plates were exposed to iodine vapors to visualize the lipid fractions, in order to quantify just sulphatide concentration.

To evaluate arylsulphatase A activity, the samples were homogenized for $2 \mathrm{~min}$ in double distilled water $(1: 20 \mathrm{w} / \mathrm{v})$ containing $0.1 \%$ Triton X 100 with Ultraturrax TP 18/10 homogenizer (Janke and Kunkel, Staufen, Germany). The homogenate was centrifuged at $20,000 \mathrm{rpm}$ at $4^{\circ} \mathrm{C}$ for 30 min using a refrigerated centrifuge (IEC Centra SR, Dunstable, Bedfordshire, England). Arylsulphatase A activity was determined biochemically according to the method of Vitaioli et al. [38] adapted from Percy and Brady [30]. The incubation mixture consisted of $0.01 \mathrm{M} \mathrm{p}$-nitrocatechol sulphate in $0.5 \mathrm{mM}$ sodium acetate buffer at $\mathrm{pH} 5.0$ containing $\mathrm{mM} \mathrm{Na} \mathrm{P}_{2} \mathrm{O}_{7}$, and $10 \% \mathrm{w} / \mathrm{v} \mathrm{NaCl}$, and $10-50 \mathrm{mg}$ of protein. The mixture was incubated at $37^{\circ} \mathrm{C}$ and the reaction was stopped after 30 min by adding $1 \mathrm{~N} \mathrm{NaOH}$. The absorbance of a reaction product, $\mathrm{p}$-nitrocatechol, was measured at $515 \mathrm{~nm}$ against a blank using a Beckman DU 40 spectrophotometer (Irvine, USA). The specific activity was expressed as nmol hydrolyzed substrate/min per mg protein, assuming $14.0 \times 10^{3}$ as the molar extinction coefficient for the hydrolysis product, p-nitrocatechol, of the substrate at $515 \mathrm{~nm}$. Protein concentrations were measured according to Bradford [8].

Median values of sulphatide concentrations and arylsulphatase A activity in each tissue specimen were compared with a non-parametric test (Mann-Whitney $U$-test). In addition, nonparametric correlations were sought out between arylsulphatase A activity and sulphatide concentration in each of the four tissue types and among the arylsulphatase $A$ activities and among sulphatide concentrations among the four tissue types. Alpha value of $\leq 0.05$ was considered as significant. In order to evaluate the relative importance of factors that could condition arylsulphatase A activity and, consequently, sulphatide concentration, a traditional conjoint analysis was carried out [16] by testing three factors: gestational age, parity and duration of active labor, each one with two possible levels established arbitrarily (respectively $\leq 40^{\text {th }}$ and $>40^{\text {th }}$ week of gestation; multiparity and nulliparity; $\leq 3$ and $>3 \mathrm{~h}$ of active labor). The premises for the reliability of results from such a conjoint analysis are that the factors examined be truly capable of conditioning the parameter being studied. Therefore, on the basis of reports in the literature [4-6] we established that we would consider gestational age, parity and duration of labor as presumably conditioning arylsulphatase $A$ activity (and consequently, sulphatide concentration) without taking into consideration other factors. The relative weight of the three factors on arylsulphatase A activity and on sulphatide concentration was expressed on a percentage scale.

\section{Results}

Values were determined in 14 cases. Median gestational age was 41 weeks (range 38-42); four patients were nulliparous; median hours of labor was $3 \mathrm{~h}$ (range 2-7 h). Median values and distribution of data on arylsulphatase A activity and sulphatide concentrations are illustrated in Figures 1 and 2. Arylsulphatase $A$ activities are expressed as nmol of hydrolyzed substrate $\mathrm{min}^{-1} \mathrm{mg}^{-1}$ of protein, and sulphatide concentrations are expressed in $\mu \mathrm{g} \mathrm{g}^{-1}$ of fresh tissue. Median arylsulphatase A activity was 4.5 (range 2.2-8.9) in cord; 1.03 (range 0.43-1.63) in membranes far from the internal uterine os; 0.615 (range 0.22-1.2) in membranes close to the internal uterine os; and 0.12 (range 0.04-0.19) in placenta. Median sulphatide concentration was 292.15 (range 51-522.8) in cord; 1462.25 (range 717.8-2287.7) in membranes far from the internal uterine os; 975.45 (range 592.1-1810.5) in membranes close to the internal uterine os; and 
Arylsulphatase $A$ activity

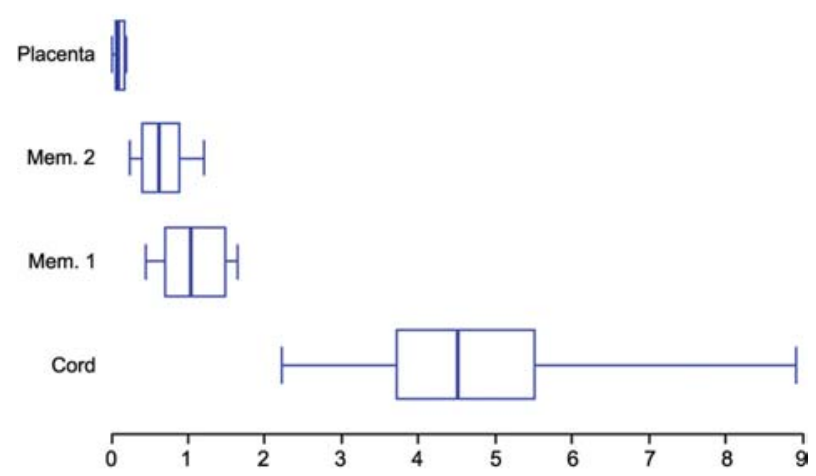

Figure 1 Box-plot of arylsulphatase A activity. Enzyme activity was determined according to Percy's method [30] and expressed as nmol of hydrolyzed substrate $\mathrm{min}^{-1} \mathrm{mg}^{-1}$ of protein. The lines within the boxes are the median values. Mem. 1: membranes far from internal uterine os. Mem. 2: membranes close to internal uterine os.

1744.35 (range 1112.6-2551.2) in placenta. Median differences between arylsulphatase A activity and sulphatide concentrations were significant, except for median concentration of sulphatides in membranes far from internal uterine os with respect to placenta (Table 1).

There was a trend on inverse correlation between arylsulphatase $A$ activities and sulphatide concentrations in the four tissues. Specifically, when the arylsulphatase A activities were low, such as those observed in the placenta and membranes, the levels of sulphatides were high. In contrast, the higher arylsulphatase A specific activity in the cord was seen with the lower content of sulphatides. However, no significant correlations were reached between arylsulphatase A activity and sulphatide concentration in any tissue type. Additionally, no correlation was found among arylsulphatase $\mathrm{A}$ activities nor

Sulphatide concentrations

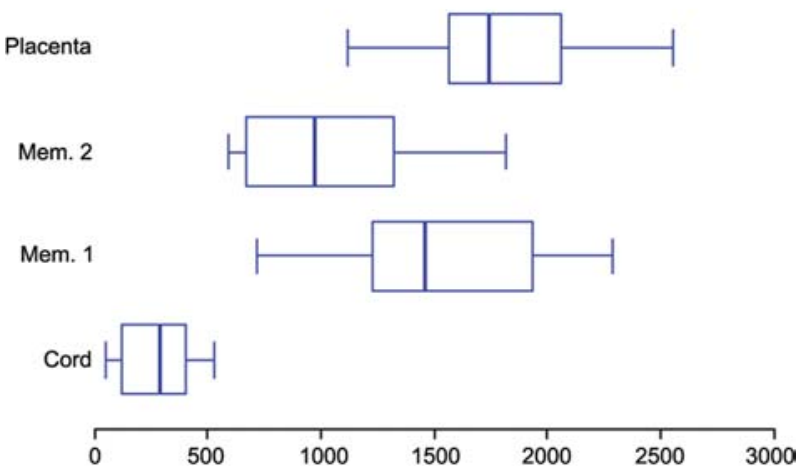

Figure 2 Box-plot of sulphatide concentrations. Sulphatide concentration was determined according to Kean's method [21] and expressed in $\mu \mathrm{g} \mathrm{g}^{-1}$ of fresh tissue. The lines within the boxes are the median values. Mem. 1: membranes far from internal uterine os. Mem. 2: membranes close to internal uterine os. among sulphatide concentrations within the different tissue types.

Results of the conjoint analysis are summarized in Figures 3 and 4, limited to arylsulphatase A activity and sulphatide concentration, respectively. It appears that no proportionately greater importance of gestational age, parity or hours of active labor conditioned arylsulphatase A activity and sulphatide concentration in each tissue specimen, with the exception of the membranes far from internal uterine os and the membranes close to internal uterine os. In the first case, duration of active labor appears to condition arylsulphatase A activity in a negative manner (i.e., reducing its activity). Parity appears to show a similar pattern although to a lesser extent, seemingly showing a greater arylsulphatase A activity in multiparas. In contrast, it appears that duration of labor does not condition sulphatide concentration in membranes close to internal uterine os with respect to parity and gestational age.

\section{Discussion}

Even if steroid hormone receptors are not assessed, the data presented here seem to support the possibility that arylsulphatase $A$ activity and, consequently, that sulphatide concentration, can be related to the various sensitivity levels of steroid hormones on placenta and membranes. This can be inferred by the trend of arylsulphatase $A$ activity and by sulphatide concentrations in the umbilical cord, a tissue that is unaffected by labor, compared with fetal adnexa and placenta. Numerous studies pointed out the presence of receptors for steroid hormones (progesterone, estrogens, cortisol) in amniochorial membranes, placenta and decidua $[10,12,15$, $22,37,40,41]$; it has also been demonstrated that arylsulphatase $A$ activity is conditioned by sex steroid hormones and by cortisol [19, 20, 23, 26, 36, 39].

Each case of labor has its own evolution and is difficult to standardize. It has been reported quite extensively, however, that the length of labor constitutes a physiological stress both on the mother and the fetus, with a probable difference in intensity according to the incretion of adrenal steroids, both in the fetus and the mother [1-3, $28,33]$. The biological effect of such steroids and particularly of cortisol, on fetal adnexa should be proportional to the number and type of receptors expressed in these tissues. At present it has not been clearly determined whether such expression is modified during labor and in relation to its progression. Goldman et al. [15] reported a difference in the expression of progesterone receptor isoforms in human decidua and fetal membranes in the presence or absence of uterine contractions. Analogous behavior could also be possible for cortisol receptors, present in both placenta and membranes [22, 37, 40] with a negative effect on arylsulphatase $A$ activity. 
Table 1 P-values for each comparison of means of the arylsulphatase A activity and sulphatide concentration.

\begin{tabular}{lll}
\hline & $\begin{array}{l}\text { Arylsulphatase } \\
\text { A activity }\end{array}$ & $\begin{array}{l}\text { Sulphatide } \\
\text { concentrations }\end{array}$ \\
\hline $\begin{array}{l}\text { Membranes next to internal uterine os vs. membranes } \\
\text { far from internal uterine os }\end{array}$ & $\mathrm{P}=0.006$ & $\mathrm{P}=0.007$ \\
Membranes next to internal uterine os vs. placenta & $\mathrm{P}<0.0001$ & $\mathrm{P}=0.0001$ \\
Membranes next to internal uterine os vs. cord & $\mathrm{P}<0.0001$ & $\mathrm{P}<0.0001$ \\
Membranes far from internal uterine os vs. placenta & $\mathrm{P}<0.0001$ & $\mathrm{P}=0.09$ \\
Membranes far from internal uterine os vs. cord & $\mathrm{P}<0.0001$ & $\mathrm{P}<0.0001$ \\
Placenta vs. cord & $\mathrm{P}<0.0001$ & $\mathrm{P}<0.0001$ \\
\hline
\end{tabular}

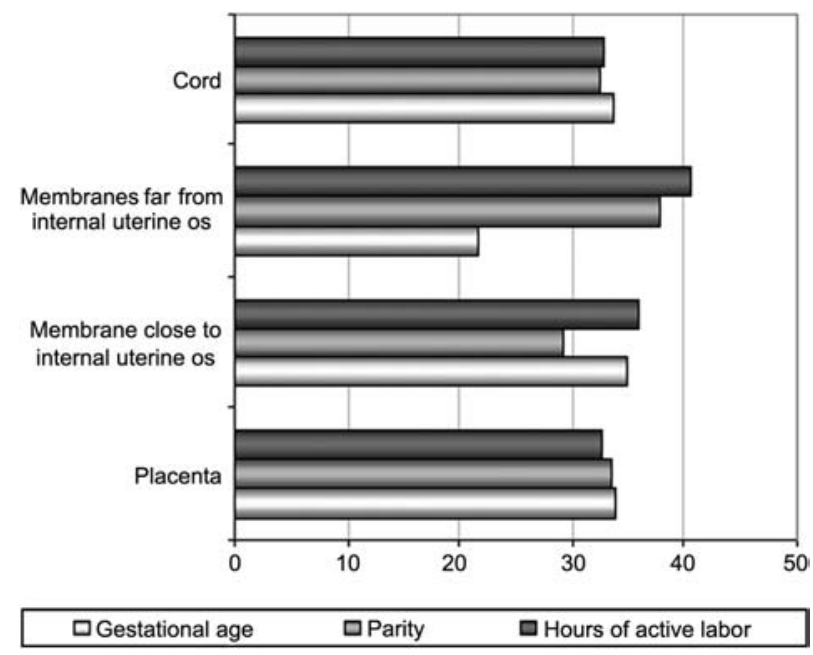

Figure 3 Relative importance of gestational age, parity and hours of active labor on arylsulphatase A activity. It appears that gestational age is relatively less important than parity and hours of active labor in affecting intensity of arylsulphatase A activity in the samples taken from membranes far from internal uterine os.

In our opinion, it is relevant that no significant correlations were found between arylsulphatase $A$ activities in the various tissue specimens, thereby confirming that they are sensitive to steroid hormones. In particular, an interesting aspect appears to be the lower activity of arylsulphatase $A$ in the placenta, which is notably more sensitive to cortisol [11,31,34] and in the membranes close to the internal uterine os (lower uterine pole) which have a different biological behavior compared with other parts of the amniochorial membranes [29].

A corollary of these results is that factors influencing the evolution of labor (parity and duration of labor) probably have a different importance in arylsulphatase $A$ activity in various tissue specimens. The data from the conjoint analysis seem to suggest a substantial indifference of gestational age, parity and duration of active labor (same proportional weight of all factors) on cord (a tissue that is not affected by labor), lower uterine pole (a tissue subject primarily to inflammatory stimuli $[13,29])$ and placenta (an organ targeted by cortisol [11, 31, 34]); conversely, the membranes far from the internal uterine os appear to be quite affected by parity and duration of active labor (perhaps due to a diverse expression of progesterone receptors during labor, as suggested by Goldman et al. [15]). However, we cannot support this hypothesis since we have not assessed the levels of steroid hormone receptors. Furthermore, the regulation of arylsulphatase A activity and sulphatides during labor remains to be investigated.

The substantial indifference of gestational age on arylsulphatase $A$ activity with respect to parity and duration of active labor, contrary to what has been previously reported for maternal decidua [5, 6], can be explained in two manners. On the one hand, the maternal decidua has a biological behavior that differs from that of the fetal adnexa [17]; in addition, the observations made on fetal adnexa were carried out after the onset of labor. Therefore, we feel that the results of our present study are not comparable with those arising from specimens of maternal decidua [5, 6]. Bakońska-Pacoń et al. [4] have reported a difference in arylsulphatase A activity in maternal blood and urine of nulliparous and multiparous women in relation to the various phases of labor. Apart from the

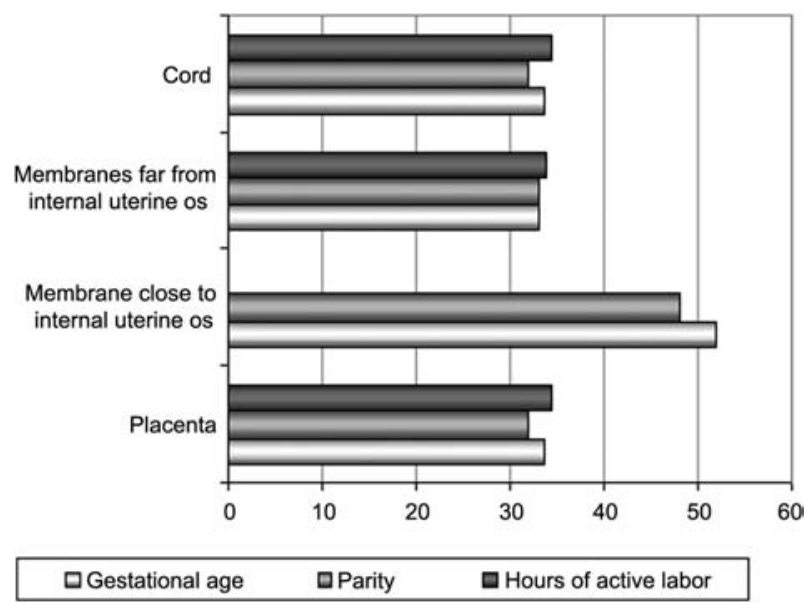

Figure 4 Relative importance of gestational age, parity and hours of active labor on sulphatide quantity. It appears that hours of active labor do not have any importance with respect to gestational age and parity in affecting the quantity of sulphatides in the samples taken from membranes close to internal uterine os. 
theoretical assumption that the phases of labor and parity may condition arylsulphatase A activity, we feel that the results reported by the latter authors cannot be compared with those set out in this study, since measurements were carried out on maternal urine and serum.

As seen in Figures 1 and 2, our study shows considerable dispersion of sulphatides data in membranes and in placenta, and in membranes and cord, with respect to arylsulphatase A activity. We feel that this aspect is related to variables inherent to the progression of labor. Although the conjoint analysis suggests the relative importance of parity, gestational age and duration of active labor, is it unable to determine precise correlations, nor to consider the weight of other hypothetical factors. This requirement calls for executing a different type of multivariate analysis, requiring many more cases.

The dispersion of sulphatide concentrations could also be attributable to variations in lipid metabolism at term [32], which could influence sulphatide quantity in each patient. This can be explained by the absent correlation between arylsulphatase A activity and sulphatide concentration in each tissue. A similar trend was also revealed in the maternal decidua of term pregnancy but not in labor [5,6], suggesting that at pregnancy termination, sulphatide concentration may depend on biosynthesis rather than on catabolism. The similar duration of active labor on the quantity (significantly lower) of sulphatides in the lower uterine pole could be attributed to inflammatory processes common to this area [13]. In summary, it seems that the presumptive factors affecting sulphatide concentrations during labor explain data dispersion, and reduce the correlation when we assess just on 14 cases.

It still remains to be discovered what function do sulphatides play in fetal adnexa. In the central nervous tissue, they are fundamental components in the organization and correct functioning of myelin, while in mouse kidney they are bound by L-Selectin of macrophages, with implications on inflammatory response [18]. Therefore, it can be postulated that sulphatides in fetal adnexa may have a function as extra-cellular "adhesive" and in mediation in cellular contact, susceptible to hormone or inflammatory control according to labor stage. This control could be limited not only to catabolism but also to biosynthesis, with variations in each tissue type of fetal adnexa.

The major limitation of this study is that we did not assess steroid hormone receptors level in relationship to arylsulphatase A activity and sulphatide concentrations. Therefore, the findings are inconclusive to explain why arylsulphatase $A$ and sulphatide concentrations vary within the sample tissues, even if a relationship with steroids should exist. Therefore, according to the literature about steroids and delivery, the study should lead to further investigation of arylsulphatase A activity and sulphatide concentrations in relationship with steroids hormone receptors during pregnancy and labor. Further investigations may also resolve the second limitation of the study, namely, the low number of cases.

In conclusion, the study demonstrates that arylsulphatase $A$ activity and sulphatide concentrations in fetal adnexa vary. It is possible that arylsulphatase A activity and, consequently, sulphatide concentration, in the tissues responsible for the onset of labor reflect the sensitivity to steroid hormones and the progression of labor.

\section{References}

[1] Arai K, Yanaihara T. Steroid hormone changes in fetal blood during labor. Am J Obstet Gynecol. 1977;127: 879-83.

[2] Bacigalupo G, Langner K, Schmidt S, Saling E. Plasma immunoreactive beta-endorphin, ACTH and cortisol concentrations in mothers and their neonates immediately after delivery - their relationship to the duration of labor. $\mathrm{J}$ Perinat Med. 1987;15:45-52.

[3] Bacigalupo G, Riese S, Rosendahl H, Saling E. Quantitative relationships between pain intensities during labor and beta-endorphin and cortisol concentrations in plasma. Decline of the hormone concentrations in the early postpartum period. J Perinat Med. 1990;18:289-96.

[4] Bakońska-Pacoń E, Karmowski A, Sobiech KA, Terpiłowski L, Kasiak J, Malik B. [Changes in arylsulphatase activity (EC 3.1.6.1) in the blood serum and urine in women during pregnancy and in the course of delivery.] Ginekol Pol. 1999;70:593-9.

[5] Baldoni E, Tomassoni D, Traini E, Indraccolo SR, Vitaioli L. Behaviour of sulphatides and arylsulphatase $A$ in the decidua of women at term pregnancy. It J Gynaecol Obstet. 2004;16:89-93.

[6] Baldoni E, Traini E, Tomassoni D, Indraccolo U, Indraccolo SR, Vitaioli L. Biochemical determinations of arylsulphatase $A$ activity and sulphatide concentrations in decidua of women at 41 and 42 weeks of gestation. Eur J Obstet Gynecol Reprod Biol. 2007;134:24-8.

[7] Bolognani L, Masserini M, Bodini PA, Bolognani-Fantin AM, Ottaviani E. Lipid composition in ganglia of mollusco. J Neurochem. 1981;36:821-5.

[8] Bradford MM. A rapid and sensitive method for quantitation of microrgram quantity principle of protein-dye binding. Anal Biochem. 1976;72:248-54.

[9] Briggs M. Lysosomal enzyme activation by steroid hormones in vivo. J Steroid Biochem. 1973;4:341-7.

[10] Bukovsky A, Cekanova M, Caudle MR, Fernando RI, Wimalasena J, Foster JS, et al. Placental expression of estrogen receptor beta and its hormone binding variant comparison with estrogen receptor alpha and a role for estrogen receptors in asymmetric division and differentiation of estrogen-dependent cells. Reprod Biol Endocrinol. 2003;1:36.

[11] Challis JRG. Mechanism of parturition and preterm labor. Obstet Gynecol Surv. 2000;55:650-60.

[12] Chibbar R, Wong S, Miller FD, Mitchell BF. Estrogen stimulates oxytocin gene expression in human chorion-decidua. J Clin Endocrinol Metab. 1995;80:567-72.

[13] El Khwad M, Stetzer B, Moore RM, Kumar D, Mercer B, Arikat $\mathrm{S}$, et al. Term human fetal membranes have a weak 
zone overlying the lower uterine pole and cervix before onset of labor. Biol Reprod. 2005;72:720-6.

[14] Goldman S, Shalev E. Progesterone receptor profile in the decidua and fetal membrane. Front Biosci. 2007;12: 634-48.

[15] Goldman S, Weiss A, Almalah I, Shalev E. Progesterone receptor expression in human decidua and fetal membranes before and after contractions: possible mechanism for functional progesterone withdrawal. Mol Hum Reprod. 2005;11:269-77.

[16] Hair JF, Black WC, Babin BJ, Anderson RE, Tatham RL. Multivariate data analysis. Sixth Edition. Chapter 7. Conjoint analysis. Pearson International Editions. Upper Saddle River, New Jersey: Copyright Pearson Education, Inc., 2006, pp. 459-551.

[17] Haluska GJ, Wells TR, Hirst JJ, Brenner RM, Sadowsky DW, Novy MJ. Progesterone receptor localization and isoforms in myometrium, decidua, and fetal membranes from Rhesus Macaques: evidence for functional progesterone withdrawal at parturition. J Soc Gynecol Invest. 2002;9: 125-36.

[18] Honke K, Zhang Y, Cheng X, Kotani N, Taniguchi N. Biological roles of sulfoglycolipids and pathophysiology of their deficiency. Glycoconj J. 2004;21:59-62.

[19] Jungalwala FB, Koul O, Stoolmiller A, Sapirstein VS. Regulation of cerebroside and sulfatide metabolism in glia cells. J Neurochem. 1985;45:191-8.

[20] Kamei K, Kubushiro K, Fujii T, Tsukazaki K, Nozawa S, Iwamori M. Menstrual cycle-associated regulation of anabolic and catabolic enzymes causes luteal phase-characteristic expression of sulfatide in human endometrium. Am J Obstet Gynecol. 1997;176:142-9.

[21] Kean EL. Rapid sensitive spectrophotometric method for quantitative determination of sulphatides. J Lipid Res. 1968;9:319-27.

[22] Lee MJ, Wang Z, Yee H, Ma Y, Swenson N, Yang L, et al. Expression and regulation of glucocorticoid receptor in human placental villouos fibroblasts. Endocrinology. 2005;146:4619-26.

[23] Marcelo AJ, Pieringer RA. Hydrocortisone regulates arylsulfatase A (cerebroside-3-sulfate-3-sulfohydrolase) by decreasing the quantity of the enzyme in cultures of cells dissociated from embryonic mouse cerebra. Neurochem Res. 1990;15:937-44.

[24] McParland PC, Taylor DJ, Bell SC. Mapping of zones of altered morphology and chorionic connective tissue cellular phenotype in human fetal membranes (amniochorion and decidua) overlying the lower uterine pole and cervix before labor at term. Am J Obstet Gynecol. 2003;189: 1481-8.

[25] Mesiano S, Welsh TN. Steroid hormone control of myometrial contractility and parturition. Semin Cell Dev Biol. 2007;18:321-31.

[26] Munakata H, Isemura M, Yoshizawa Z. Hormonal effects on the activities of glycosidases in the endometrium of rabbit uterus. Biochem Med Metab Biol. 1986;35:179-83.

[27] Norman JE, Bollapragada S, Yuan M, Nelson SM. Inflammatory pathways in the mechanism of parturition. BMC Pregnancy Childbirth. 2007;7(Suppl 1):S7.
[28] Nwosu UC, Wallach EE, Feldman JD, Bongiovanni AM. Parturition-induced changes in maternal plasma cortisol levels. Obstet Gynecol. 1975;46:263-7.

[29] Osman I, Young A, Jordan F, Greer IA, Norman JE. Leukocyte density and proinflammatory mediator expression in regional human fetal membranes and decidua before and during labor at term. J Soc Gynecol Invest. 2006;13: 97-103.

[30] Percy AK, Brady RO. Metachromatic leukodystrophy diagnosis with samples of venous blood. Science. 1968;161: 594-5.

[31] Reis FM, Fadalti M, Florio P, Petraglia F. Putative role of placental corticotropin-releasing factor in the mechanisms of human parturition. J Soc Gynecol Invest. 1999;6: 109-19.

[32] Sattar N, Greer IA, Louden J, Lindsay G, Mcconnell M, Sheperd J, et al. Lipoprotein subfraction changes in normal pregnancy: threshold effect of plasma triglyceride on appearance of small, dense low density lipoprotein. J Clin Endocrinol Metab. 1997;82:2483-91.

[33] Sippell WG, Dörr HG, Becker H, Bidlingmaier F, Mickan H, Holzmann K. Simultaneous determination of seven unconjugated steroids in maternal venous and umbilical arterial and venous serum in elective and emergency cesarean section at term. Am J Obstet Gynecol. 1979;135:530-42.

[34] Smith R. Parturition. N Engl J Med. 2007;356:271-83.

[35] Smith R, Van Helden D, Hirst J, Zakar T, Read M, Chan $\mathrm{EC}$, et al. Pathological interactions with the timing of birth and uterine activation. Aust N Z J Obstet Gynaecol. 2007;47:430-7.

[36] Stephens JL, Pieringer RA. Regulation of arylsulphatase A and sulphogalactolipid turnover by cortisol in myelinogenic cultures of cells dissociated from embryonic mouse brain. Biochem J. 1984;219:689-97.

[37] Sun M, Ramirez M, Challis JR, Gibb W. Immunohistochemical localization of the glucocorticoid receptor in human fetal membranes and decidua at term and preterm delivery. J Endocrinol. 1996;149:243-8.

[38] Vitaioli L, Baldoni E, Bellini-Cardellini L. Arylsulphatase activity in the frog oviduct during the recovery phase of the reproductive cycle. Cell Mol Biol. 1986;32:187-93.

[39] Vitaioli L, Gobbetti A, Baldoni E. Arylsulphatase A activity and sulphatide concentration in the female rabbit oviduct are under physiological hormonal influence. Histochem J. 1996;28:149-56.

[40] Weisbart M, Huntley FM. The presence of cortisol receptors in the human amnion. J Steroid Biochem Mol Biol. 1997;63:339-44.

[41] Wu WX, Ma XH, Smith GC, Nathanielsz PW. Differential distribution of ERalpha and ERbeta mRNA in intrauterine tissues of the pregnant rhesus monkey. Am J Physiol Cell Physiol. 2000;278:C190-8.

The authors stated that there are no conflicts of interest regarding the publication of this article.

Received September 3, 2008. Revised March 3, 2009. Accepted March 5, 2009. Previously published online June 3, 2009. 